\title{
Escape Beyond Mid-Chin
}

National Cancer Institute

\section{Source}

National Cancer Institute. Escape Beyond Mid-Chin. NCI Thesaurus. Code C127188.

A finding of escape beyond mid-chin during swallowing. 